\title{
Growth factors and their receptors derived from human amniotic cells in vitro
}

\author{
Zofia Grzywocz ${ }^{1}$, Ewa Pius-Sadowska ${ }^{2}$, Patrycja Klos ${ }^{2}$, Marek Gryzik ${ }^{1}$, \\ Danuta Wasilewska ${ }^{1}$, Barbara Aleksandrowicz ${ }^{3}$, Malgorzata Dworczynska ${ }^{3}$, \\ Stanislawa Sabalinska ${ }^{4}$, Grazyna Hoser ${ }^{1}$, Boguslaw Machalinski ${ }^{2}$, Jerzy Kawiak ${ }^{1}$
}

${ }^{1}$ Innovative Economy Operational Program: Innovative methods of stem cells application in medicine, The Medical Centre for Postgraduate Education, Warsaw, Poland

${ }^{2}$ Department of General Pathology, Pomeranian Medical University, Szczecin, Poland ${ }^{3}$ Clinical Department of Midwifery and Gynaecology, Bielanski Hospital, Warsaw, Poland

${ }^{4}$ Department of Biomedical Systems and Technologies, Nalecz Institute of Biocybernetics and Biomedical Engineering, Polish Academy of Science, Warsaw, Poland

\begin{abstract}
In vitro studies have shown that amnion-produced growth factors participated in angiogenesis, re-epithelialization, and immunomodulation. The aim of our study was to investigate the growth factors and receptors produced by human amnion tissue and amniotic cells. Human amnions (hAM) were isolated, and amnion circles were dissected for in vitro analysis. Some amnion fragments were digested by the use of different methods to obtain two cell fractions, which were analysed for mesenchymal and epithelial cell markers. Amniotic circles and human amniotic cell fractions were cultured in a protein-free medium. Proteins secreted into the culture medium were analysed with a human growth factor antibody array. Conditioned culture media were added to human umbilical vein epithelial cells (HUVECs) to test for stimulation of migration (scratch test) and proliferation (Ki67 expression). Fraction 1 cells expressed both cytokeratin and mesenchymal cell markers which indicated that it was composed of a mixture of human amnion epithelial cells (hAECs) and mesenchymal stromal cells (hAMSCs). Fraction 2 cells mainly expressed cytokeratin and, therefore, were designed as hAECs. Secretion of proteins by the cultured cells increased with time. The hAM cultures secreted EGF-R, IGF, and IGFBP-2, -3 and -6; Cell Fraction 1 secreted NT-4, whereas Cell Fraction 2 secreted G-CSF, M-CSF, and PDGF. Conditioned media of hAM cultures stimulated HUVECs migration. We have showed for the first time that human amnions and amniotic cells secreted IGFBP-6, MCSF-R, PDGF-AB, FGF-6, IGFBP-4, NT-4, and VEGF-R3. We found that Cell Fraction 1, Cell Fraction 2, and the whole amnion secreted different proteins, possibly due to different proportions of amnion-derived cells and different cell-cell interactions. The hAM cell factors remained functional in vitro and induced intensified migration of HUVECs. The growth factors and receptors found in amnion or amniotic cell media might be used for regenerative medicine. (Folia Histochemica et Cytobiologica 2014, Vol. 52, No. 3, 163-170)
\end{abstract}

Key words: human amnion; amniotic epithelial cells; amniotic mesenchymal stromal cells; cell culture; growth factors

Correspondence address: Prof. J. Kawiak

The Medical Centre for Postgraduate Education 99/103 Marymoncka St., 01-813 Warsaw, Poland tel.: +482256938 67, fax: +48225693899

e-mail: jkawiak@ibib.waw.pl

\section{Introduction}

Human foetal membranes, the amnion and chorion, enclose the foetus in the amniotic cavity. The inner surface of the human amnion (hAM), which faces the amniotic cavity, comprises human amniotic epithelial cells (hAECs). The outer layer of the hAM comprises human amniotic mesenchymal stromal cells (hMSCs), which are surrounded by an intercellular matrix. One 
of the functions of amniotic cells is the release of growth factors and cytokines, which regulate different processes during the development of the embryo [1].

During foetal development, an important regulatory factor is vascular endothelial growth factor (VEGF). VEGF increases the permeability of the human amnion [2]. During pregnancy, amniotic fluid is constantly exchanged and deregulation of amniotic fluid volume may result in polyhydramnios or oligohydramnios, which are associated with preterm birth and perinatal morbidity or mortality [2].

In vitro studies have shown that amnion-produced growth factors participated in angiogenesis, re-epithelialization, and immunomodulation [3]. Some factors stimulate cell differentiation and proliferation, like macrophage colony-stimulating factor (M-CSF), which was detected in cultures of human amniocytes [4]. Other factors, like IGF-2, were found on mRNA level in human amniotic epithelial cells, where they may promote proliferation [5].

This study aimed to determine the capacity of human amnions (hAMs) and isolated human amniotic cells (hAMCs) to produce growth factors and receptors. Cell fractions were further isolated to test whether cells in different fractions showed differences in the production of growth factors. We assumed that the relative proportions of the isolated cell fractions may affect various amounts of growth factors found to be released by amniotic cells in vitro.

\section{Material and methods}

Experiments were performed with the approval of the Bioethics Commission at The Medical Centre of Postgraduate Education (accepted on December 5, 2012). Seven full-term human placentas were obtained from healthy women after obtaining informed written consent. We analysed seven amniotic samples; four samples were used for the human growth factor antibody array and three were used for cytometric analyses.

Isolation of amnions and amniotic cells. Cell fractions were isolated according to a protocol described previously, by Soncini et al. [6], with minor modifications. Amnions were obtained from the Clinical Department of Midwifery and Gynaecology, Bielanski Hospital, Warsaw, Poland. Amnions were mechanically separated from placentas and cut into pieces. These fragments were washed twice in phosphate-buffered saline (PBS, $\mathrm{pH}=7.4$, Sigma-Aldrich, St. Louis, MO, USA) and incubated for $30 \mathrm{~min}$ in PBS with penicillin $\left(7.5 \times 10^{5} \mathrm{IU} / \mathrm{mL}\right.$, Polfa Tarchomin, Poland), streptomycin $(0.25 \mathrm{~g} / \mathrm{mL}$, Polfa $)$, and nystatin $(2.5 \mathrm{mg} / \mathrm{mL}$, Sigma-Aldrich). After another wash with PBS, the amniotic fragments were cut with a Biopsy Punch (Miltex,
York, PA, USA) to obtain 5-mm wide circles of tissue, which were placed in a 4 wells in 48 -well culture plate (ten circles per well). The remainder of the amniotic fragments (on average, $1.84 \mathrm{~g}$ of tissue) was divided in half, and each portion was dissociated enzymatically. The first portion of amniotic fragments was incubated in a mixture of $2.4 \mathrm{U} / \mathrm{mL}$ dispase (Sigma-Aldrich) and $20 \mu \mathrm{g} / \mathrm{mL}$ deoxyribonuclease I (Sigma-Aldrich) in PBS for $7 \mathrm{~min}$ at $37^{\circ} \mathrm{C}$. Then, the mixture was incubated with type I clostridial collagenase $(0.75 \mathrm{mg} / \mathrm{mL}$, Sigma-Aldrich) in PBS for $3 \mathrm{~h}$ at $37^{\circ} \mathrm{C}$. Next, the cells were transferred to a new test tube with PBS and $2 \mathrm{mM}$ EDTA, and centrifuged for $5 \mathrm{~min}$ at $230 \mathrm{~g}$. Then, the pellet was washed with physiological $\mathrm{NaCl}$ solution (PS-NaCl), and filtered through a sterile nylon Cell Strainer (pore size $100 \mu \mathrm{m}$; BD, Franklin Lake, NJ, USA). The resulting cell suspension was designated Cell Fraction 1. The remaining portion of amniotic membrane fragments was incubated for 2-5 min in $0.25 \%$ trypsin and EDTA (Invitrogen, Grand Island, NY, USA) at $37^{\circ} \mathrm{C}$. Then, cells were suspended in $2.5 \%$ human albumin in PBS (SIS Biomed, Warsaw, Poland) and centrifuged for $5 \mathrm{~min}$ at $230 \mathrm{~g}$. The cell pellet was washed in PS-NaCl and filtered through a Cell Strainer (pore size $100 \mu \mathrm{m}$, BD). The resulting cells were designated Cell Fraction 2.

Cultures of amniotic circles and isolated cell fractions. Amniotic circles (ten per well) and isolated cell fractions were separately incubated and cultured in a protein-free RPMI 1640 medium (Gibco, Grand Island, NY, USA) with the standard addition of penicillin/streptomycin in a humidified $5 \% \mathrm{CO}_{2}$ atmosphere at $37^{\circ} \mathrm{C}$. Cell Fraction 1 comprised an average of $0.45 \times 10^{5}$ cells suspended in $0.6 \mathrm{~mL}$ per well; Cell Fraction 2 comprised an average of $0.3 \times 10^{6}$ cells suspended in $0.6 \mathrm{~mL}$ per well. Different cell fractions and tissue cultures were incubated for 3, 6, 24 or 48 hours. The 3 hours incubation time point was treated as baseline, and incubation for 48 hours was the end point. We did not test longer cell cultures to avoid changes in the original cell properties. After the indicated culture times, the conditioned culture media were collected and centrifuged for $10 \mathrm{~min}$ at $1000 \mathrm{~g}$; the culture media were then aliquoted and frozen at $-80^{\circ} \mathrm{C}$ until further analysis.

Isolation of human umbilical vein endothelial cells (HUVEC). Umbilical cords obtained from placenta donors were washed with PBS and then filled with Hanks buffer (Sigma-Aldrich) to remove erythrocytes. Next, umbilical veins were filled with dispase $(0.96 \mathrm{mg} / \mathrm{mL}$, Gibco $)$ and incubated for $15 \mathrm{~min}$ at $37^{\circ} \mathrm{C}$ in a heated bath. The liberated cells were removed and centrifuged. Then, the umbilical veins were washed with Medium 199 (Sigma-Aldrich) to retrieve cells, and the cell suspension was centrifuged at $230 \mathrm{~g}$. The cells were pooled and cultured for 4-5 h in Medium 199 , and, finally, the culture medium was changed to remove non-adherent cells. 
Table 1. Growth factors, their receptors and other proteins measured by the protein array

\begin{tabular}{|l|l|}
\hline Growth factor families & Tested members \\
\hline Epidermal and fibroblasts growth factors & *HB-EGF *EGF-2 EGF-R *bFGF *FGF-4 *FGF-6 *FGF-7 \\
\hline Neural and glial growth factors & *bNGF *GDNF *NT-3 NT-4 \\
\hline Angiogenic growth factors & *VEGF *VEGF-D *VEGF-R2 *VEGF-R3 PLGF \\
\hline Haematopoietic growth factors & G-CSF *GM-CSF M-CSF M-CSF-R *SCF *SCF-R \\
\hline Insulin-like growth factors & *IGF-1 IGF-2 *IGF-ISR *IGFBP-1 IGFBP-2 IGFBP-3 *IGFBP-4 IGFBP-6 \\
\hline Platelet derived growth factors & *PDGF-AA PDGF-AB *PDGF-BB *PDGFRa *PDGFRb \\
\hline Transforming growth factors & *TGF-a *TGF-b *TGF-b2 *TGF-b3 \\
\hline Other proteins & *HGF *AR \\
\hline
\end{tabular}

Asterisk (*) denote proteins found in the culture media of human amniotic membranes, Cell Fraction 1 and Cell Fraction 2, which concentrations did not change during the time of culture duration. Assays were performed as described in Methods

Cytometric analysis of amniotic and endothelial cells. Cell Fractions 1 and 2 were tested for the presence of mesenchymal cell surface markers by probing with specific antibodies conjugated to allophycocyanin (APC), phycoerythrin (PE) or fluorescein isothiocyanate (FITC), including: anti-CD90 APC (clone 5E10, BD); anti-CD73 PE (clone TY/23, BD); anti-CD105 PE (clone 266, BD), and antibodies against epithelial cytoplasmatic markers, anti-cytokeratins 4/5/6/8/10/13/18 FITC (clone C11, AbD Serotec, Kidilington, UK). Additionally, Cell Fraction 1 was probed with anti-CD45 FITC (clone HI30, BD) and anti-CD34 PE (clone $581, \mathrm{BD})$. Isotype controls were: $\mathrm{PE}$ isotype control (clone MOPC-21, BD); FITC isotype control (clone MOPC-21, $\mathrm{BD}$ ); and APC isotype control (clone MOPC-21, BD).

HUVECs were probed with an antibody against the Ki67 proliferation marker, anti-Ki67 PE (clone B56, BD) and with the PE isotype control (clone B56, BD).

Labelled cells were analysed by flow cytometry with the FACSCanto II cytometer (BD) and FacsDiva software (BD).

Cytokine antibody array. We analysed the proteins in the conditioned culture media with a human growth factor antibody array (RayBiotech, Atlanta, GA, USA). The array can detect 41 growth factors and receptors (Table 1), and the assay was performed according to the manufacturers' protocol. Briefly, the analytic membrane was blocked in Blocking Buffer for $30 \mathrm{~min}$; then, it was incubated with the sample at $4^{\circ} \mathrm{C}$ overnight, washed five times in buffer, and incubated in the biotin-conjugated antibody solution for $90 \mathrm{~min}$. The membrane was then washed five times and incubated in horseradish peroxidase-(HRP)-conjugated streptavidin for $90 \mathrm{~min}$, followed by another wash procedure. Finally, the array was incubated in a mixture of Detection Buffers for $2 \mathrm{~min}$, and visualised with a chemiluminescence imaging system (UVP camera, Gel Doc - Imaging System, BioRad, Hercules, CA, USA).

Image-densitometry analyses for the cytokine antibody array were performed with ImageJ software (NIH, Bethesda,
MD, USA) and the Protein Array Analyser plug-in. The intensity of each spot was quantified, and relative expression levels between proteins were calculated. The spot intensity was quantified in arbitrary densitometry units; the positive and negative controls were used to determine relative values. All values were multiplied by 100 .

Scratch test. Isolated HUVECs were placed in a 12-well dish and cultured for three days in Medium 199 (Sigma-Aldrich) with $20 \%$ foetal bovine serum (Gibco), human endothelial cell growth factor supplement $(1 \mu \mathrm{g} / \mathrm{mL}$ Millipore, Darmstadt, Germany), HEPES (0.2 $\mu \mathrm{g} / \mathrm{mL}$ Sigma-Aldrich), and the standard concentrations of antibiotics. After cell cultures achieved confluence, a 3-mm scratch was made on the bottom of each well to create a clear, cell-free line. Then, after $24 \mathrm{~h}$ of culture, hAM-conditioned medium was collected, and aliquots were added $(10 \% \mathrm{v} / \mathrm{v})$ to the six HUVEC wells, and HUVECs were cultured for another three days. To the six other HUVEC wells (controls) 10\% (v/v) RPMI 1640 protein-free medium was added. At $24 \mathrm{~h}$ after making the scratch, cell growth into the clear area was observed with an inverted microscope (IX 71, Olympus, Tokyo, Japan), and the width of the scratch was measured with cellSence Dimension software (Olympus).

Statistical analysis. The growth factor antibody array results were expressed as the medians and interquartile range (25-75\%). Groups were compared with the Mann-Whitney test. Statistical significance was set at $p<0.05$.

\section{Results}

\section{Characteristics of amniotic cells}

In Cell Fraction 1, most cells stained positively for the following mesenchymal cell markers (median percentages): CD73 (86\%), CD90 (19.3\%), and CD105 (2.2\%). Only $8.6 \%$ of Fraction 1 cells expres- 
Table 2. Expression of mesenchymal and epithelial cell markers in the fractions of cells isolated from human amnions

\begin{tabular}{|l|c|c|c|}
\hline Cells & Marker & Median (\%) & P25-P75 (\%) \\
\hline \multirow{3}{*}{ Cell Fraction 1 } & CD73+ & 86.0 & $50.9-91.6$ \\
& CD90+ & 19.3 & $16.3-23.7$ \\
& CK 4/5/6/8/10/13/18+ & 8.6 & $6.6-53.7$ \\
& CD105+ & 2.2 & $1.5-47.3$ \\
\hline \multirow{4}{*}{ Cell Fraction 2 } & CD73+ & 1.5 & $1.5-5.4$ \\
& CD $90+$ & 11.8 & $10.3-26.8$ \\
& CK 4/5/6/8/10/13/18+ & 98.4 & $97.1-99.0$ \\
& CD105+ & 4.1 & $2.6-8.8$ \\
& CD45+ & 0.2 & $0.1-0.8$ \\
\hline
\end{tabular}

Data are expressed in percentages and were obtained from 3 independent experiments. Cell Fraction 1 - human amniotic cells isolated with dispase and collagenase; Cell Fraction 2 - human amniotic cells isolated with trypsin; CK — cytokeratin

Table 3. Proportion of cells in human amniotic membranes

\begin{tabular}{|l|c|c|c|}
\hline & Mesenchymal cells (CD73+) & $\begin{array}{c}\text { Epithelial cells } \\
\text { CK 4/5/6/8/10/13/18+ }\end{array}$ & Total in each fraction \\
\hline & & & 0.09 \\
\hline Cell Fraction 1 & 0.86 & 0.98 & 0.94 \\
\hline Cell Fraction 2 & 0.02 & 1.07 & 1.00 \\
\hline Catal of both fractions & 0.88 & 0.55 & 1.94 \\
\hline
\end{tabular}

Description as for Figure 1 and Table 2. Data were obtained from 3 independent experiments

sed the epithelial cell markers, i.e. cytokeratins 4/5/6/8/10/13/18.

In Cell Fraction 2, most cells (98.4\%) expressed the epithelial cell markers, cytokeratins 4/5/6/8/10/13/18, and only few cells expressed mesenchymal cell markers: CD73, CD90 and CD105 (Table 2).

We calculated that the intact amniotic membrane circles comprised of equal hAMSCs and hAECs cell markers (Table 3).

\section{Presence of growth factors and receptors in conditioned media}

The use of cytokine antibody array revealed some individual differences among the amnions of different women. However, all tested proteins were present in the supernatants (Table 1). In this work, we focused only on statistically significant changes over time in the levels of growth factors and their receptors (Table 4). From both the intact human amnion circles and the isolated amnion cells (Fractions 1 and 2), we found some factors released to the culture medium that had not been reported previously, including IGFBP-6, $\mathrm{M}$-CSF receptor (M-CSF-R), heterodimer of platelet derived growth factors $\mathrm{AB}$ (PDGF-AB), fibroblast growth factor-6 (FGF-6), IGFBP-4, neurotrophin-4 (NT-4), and VEGF receptor-3 (VEGF-R3), as shown in Table 5.

\section{Presence of growth factors and receptors in human amnion culture media}

Relative changes in the secretion of growth factors and receptors were measured over time, starting at $3 \mathrm{~h}$ of culture. In the course of culturing hAMs, we observed in culture medium increasing levels of IGF-2, IGFBPs-2, -3, and -6, and the EGF receptor (EGF-R) (Table 4).

The relative concentration of IGFBP- 2 increased by about 4-fold from 3 to $48 \mathrm{~h}$. However, IGFBP-3 showed a much greater concentration increase; between 3 and 48 h, IGFBP-3 level increased up to 41-fold, and between 6 and $48 \mathrm{~h}-13$-fold. The relative IGFBP- 6 concentration was augmented nearly 6 -fold between 6 and $48 \mathrm{~h}$. The relative concentration of IGF-2 increased about 1.5 -fold between 6 and $48 \mathrm{~h}$ (Table 4).

The EGF-R concentration was about 3 -fold higher at $48 \mathrm{~h}$ compared to the value at $24 \mathrm{~h}$. These observations suggested that hAM cultures continuously produced these factors within the tested period of time. 
Table 4. Concentrations of proteins in conditioned media of human amnions and isolated amniotic cell cultures

\begin{tabular}{|c|c|c|c|c|}
\hline & \multicolumn{4}{|c|}{ Duration of cultures } \\
\hline & 3 hours & 6 hours & 24 hours & 48 hours \\
\hline \multicolumn{5}{|c|}{ Whole human amniotic membranes } \\
\hline EGF-R & $\begin{array}{c}0.10 \\
(0.00-0.30)\end{array}$ & $\begin{array}{c}0.00 \\
(0.00-0.11)\end{array}$ & $\begin{array}{c}0.41^{\#} \\
(0.31-0.71)\end{array}$ & $\begin{array}{c}1.19^{\#} \\
(0.86-1.53)\end{array}$ \\
\hline IGF-2 & $\begin{array}{c}1.7 \\
(0.50-3.90)\end{array}$ & $\begin{array}{c}1.38 \\
(0.95-1.70)\end{array}$ & $\begin{array}{c}1.82 \\
(1.17-3.38)\end{array}$ & $\begin{array}{c}2.30^{\#} \\
(1.92-2.59)\end{array}$ \\
\hline IGFBP-2 & $\begin{array}{c}1.75 \\
(0.51-3.89)\end{array}$ & $\begin{array}{c}3.71^{*} \\
(2.03-5.28)\end{array}$ & $\begin{array}{c}4.73 \\
(2.74-6.73)\end{array}$ & $\begin{array}{c}7.26^{*} \\
(5.60-7.66)\end{array}$ \\
\hline IGFBP-3 & $\begin{array}{c}0.05 \\
(0.00-0.26)\end{array}$ & $\begin{array}{c}0.16^{*} \\
(0.00-5.00)\end{array}$ & $\begin{array}{c}1.38 \\
(0.53-1.93)\end{array}$ & $\begin{array}{c}2.03^{*} \\
(1.20-2.56)\end{array}$ \\
\hline IGFBP-6 & $\begin{array}{c}0.30 \\
(0.10-0.80) \\
\end{array}$ & $\begin{array}{c}0.27 \\
(0.06-0.60) \\
\end{array}$ & $\begin{array}{c}0.90 \\
(0.46-1.36) \\
\end{array}$ & $\begin{array}{c}1.54^{*} \\
(1.05-2.05) \\
\end{array}$ \\
\hline \multicolumn{5}{|c|}{ Cell Fraction 1} \\
\hline NT-4 & $\begin{array}{c}0.20 \\
(0.20-0.30)\end{array}$ & $\begin{array}{c}0.14 \\
(0.01-0.28)\end{array}$ & $\begin{array}{c}0.36^{\#} \\
(0.31-0.39)\end{array}$ & $\begin{array}{c}0.19 \\
(0.04-0.39)\end{array}$ \\
\hline \multicolumn{5}{|c|}{ Cell Fraction 2} \\
\hline M-CSF & $\begin{array}{c}0.60 \\
(0.50-0.70)\end{array}$ & $\begin{array}{c}0.66 \\
(0.57-0.79)\end{array}$ & $\begin{array}{c}1.11^{\#} \\
(0.92-1.25)\end{array}$ & $\begin{array}{c}0.80 \\
(0.47-0.99)\end{array}$ \\
\hline M-CSF-R & $\begin{array}{c}0.60 \\
(0.31-0.74)\end{array}$ & $\begin{array}{c}0.60 \\
(0.45-0.78)\end{array}$ & $\begin{array}{c}0.78^{*} \\
(0.76-1.01)\end{array}$ & $\begin{array}{c}0.60 \\
(0.41-0.82)\end{array}$ \\
\hline PDGF-AB & $\begin{array}{c}0.13 \\
(0.06-0.15)\end{array}$ & $\begin{array}{c}0.25 \\
(0.15-0.29)\end{array}$ & $\begin{array}{c}0.31^{*} \\
(0.29-0.34)\end{array}$ & $\begin{array}{c}0.30^{*} \\
(0.24-0.36)\end{array}$ \\
\hline PLGF & $\begin{array}{c}0.60 \\
(0.40-1.10)\end{array}$ & $\begin{array}{c}0.40 \\
(0.34-0.55)\end{array}$ & $\begin{array}{c}0.26 \\
(0.24-0.32)\end{array}$ & $\begin{array}{c}0.41^{\$} \\
(0.38-0.45)\end{array}$ \\
\hline G-CSF & $\begin{array}{c}0.26 \\
(0.18-0.44)\end{array}$ & $\begin{array}{c}0.44 \\
(0.27-0.95)\end{array}$ & $\begin{array}{c}0.56 \\
(0.40-0.83)\end{array}$ & $\begin{array}{c}0.58^{*} \\
(0.47-0.86)\end{array}$ \\
\hline
\end{tabular}

Human amniotic membranes and isolated Cell Fraction 1 and 2 cells were cultured for 3, 6, 24 or 48 hours, and culture media were collected and processed as described in Methods. Data represent median values and P25-P75 $(\mathrm{n}=4) .{ }^{*}, \#$, \$Significantly different results versus $3 \mathrm{~h}, 6 \mathrm{~h}$ or $24 \mathrm{~h}$ values, respectively, $p<0.05$

Table 5. Novel proteins detected in the conditioned culture media of human amniotic membranes and fractions of isolated amniotic cells

\begin{tabular}{|l|l|}
\hline Growth factor & Cells \\
\hline IGFBP-6 & hAM \\
\hline FGF-6 & Cell Fraction 1 \\
\hline IGFBP-4 & Cell Fraction 1 \\
\hline NT-4 & Cell Fraction 1 \\
\hline VEGF-R3 & Cell Fraction 1 \\
\hline M-CSF-R & Cell Fraction 2 \\
\hline PDGF-AB & Cell Fraction 2 \\
\hline
\end{tabular}

Description as for Table 2, $\mathrm{n}=4$. These proteins were not detected in other studies (see Discussion)

In some cases, growth factors (e.g., EGF-R, IGF-2, and IGFBP-6) exhibited lower concentrations in the conditioned media at $6 \mathrm{~h}$ than at $3 \mathrm{~h}$, however, these differences were not statistically significant (Table 4).

\section{Cell Fraction 2 culture medium}

Cell Fraction 2, which contained mainly epithelial cells, expressed haematopoietic growth factors, including granulocyte colony-stimulating factor (G-CSF), M-CSF, PDGF, and the angiogenesis regulator, PLGF (Table 4).

The G-CSF concentration level doubled between 3 and $48 \mathrm{~h}$. The relative M-CSF concentration increased 1.5 -fold between 6 and $24 \mathrm{~h}$; the level of M-CSF receptors (M-CSF-R) increased relatively little. The heterodimeric PDGF-AB level doubled between 3 and $24 \mathrm{~h}$. The level of PLGF increased 1.6-fold between 24 and $48 \mathrm{~h}$. The release of these factors into the culture medium suggested that factors released by the amniotic epithelial cell fraction may regulate locally blood cell differentiation and vasculogenesis.

\section{Cell Fraction 1 culture medium}

Cell fraction 1 contained mostly mesenchymal cells. Among all 41 tested proteins, only the relative con- 


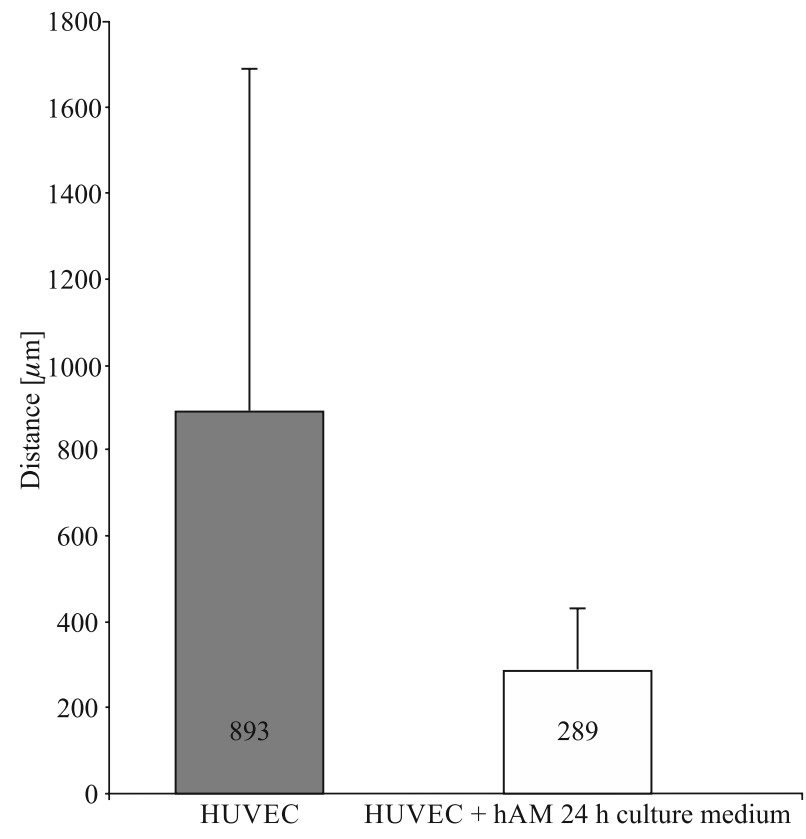

Figure 1. Scratch test of human umbilical cord vessel epithelium cells. HUVEC cells were incubated with the hAM $24 \mathrm{~h}$ culture medium as described in Methods. Y axis: distance covered by HUVEC cells. Data show median values and P25 (HUVEC P25 $=796 \mu \mathrm{m}$; HUVEC + hAM $24 \mathrm{~h}$ culture medium P25 $=145 \mu \mathrm{m}$ ) of the distance covered by the cells from the edge of the scratch. $(\mathrm{n}=6 ; p<0.05)$. Abbreviations: hAM — human amniotic membrane; HUVEC - human umbilical cord vessel epithelium cells

centration of NT-4 increased statistically significantly during the study time period. Between 6 and $24 \mathrm{~h}$, NT-4 increased by 2.6 -fold. Because the amnion has no neural supply, this finding suggested that NT-4 played an important local role in the function of the amnion epithelium, possibly related to apoptosis.

\section{Factors released by $h A M$ cells affect function of cultured HUVECs}

When 24-h conditioned hAM medium was added at $10 \%$ to HUVEC cultures, the growth of HUVECs over the scratch regions was, on average, 3 times greater than in control wells (cell growth covered $893 \mu \mathrm{m} v s .289 \mu \mathrm{m}$, respectively; $p<0.05$; Figure 1).

To support the finding that conditioned medium induced more intensive cell growth, we tested the cellular expression of Ki67, a proliferation marker. The HUVEC cultures that received 24-h conditioned hAM culture medium contained an average of 1.6-fold more Ki67-positive cells than control cultures ( $8 \%$ vs. $5 \%$, respectively), however, the differences were not statistically significant. Altogether, these results suggested that the conditioned hAM culture medium contained factors that increased the mobility of HUVEC cells.

\section{Discussion}

Several previous studies reported that amniotic membranes secreted interleukins [1,3,7-11], however, the secretion of growth factors was less characterized. Therefore, we measured 41 different growth factors and receptors that were known to be present in other tissues. Some of the tested regulatory proteins were released in Cell Fraction 1 and 2 cultures, others were only produced by hAM. In general, we observed relative increases in the concentration of growth factors in the culture medium over time.

The original data, reported for the first time in this paper, was the finding that cultured human amnion secreted: FGF-6, NT-4, VEGF-R3, M-SCF-R, IGFBP-4, IGFBP-6, and PDGF-AB. The function of these growth factors in amnion is unknown. However, we hypothesize that their presence may depend on stress or experimental conditions, due to the fact that these growth factors are often released as a response to injury. Some of these factors may have effects within regenerating damaged tissue. For example, knock-out mice $F G F-6^{-/}$after skeletal muscle injury revealed fibrosis and myotube degeneration demonstrating that FGF-6 seems to be component of the muscle regenerative machinery [12]. Experiment on NT4/5 knock-out mice revealed the role of NT-4 in regeneration of axons in peripheral nerves [13]. Disconnection of lymph vessels in adult mice suggested activation of VEGF receptor 3 in the following reconnection of the collecting lymph vessels in the animals [14]. The in vitro study on human periodontal ligament fibroblasts showed that PDGF-AB had mitogenic effect on the cells [15].

Several factors were described previously as amnion products; e.g., EGF-R was expressed in rat foetal membranes on days 18-22 of gestation [16] and human amniotic fluid was shown to contain $0.745 \pm$ $0.0056 \mathrm{pg} / \mathrm{mL}$ of epithelial growth factor (EGF) [17]. It was suggested that EGF could modulate the onset of parturition since EGF levels in human amniotic fluid increase steadily from 30 to 40 weeks of gestation [17], thus, EGF-R secreted by human amnions may have a regulatory function. We speculated that the release of EGF-R near the amnion surface may protect amnion epithelial cells against EGF activity. Moreover, it was reported that increased and sustained levels of EGF-R and PDGF-R proteins accelerated wound healing [18]; thus, we reasoned that EGF-R may have an additional function of protecting the amnion from delivery stress. 
Generally, our data stress the role of IGF and IGF-BPs secreted by amnion during human development. Our data on the expression of IGFBP-3 protein in human amniotic membrane tissue confirmed previous studies based on mRNA assays [19], however, some of the earlier observations were negative [20]. Our observation that the concentration of IGFBP-6 increased over the duration of culture may suggest a functional regulatory role for the concomitant rise of IGF-2 levels, because IGFBP-6 has a high affinity for IGF-2 [21]. Also, IGFBP-3 has high affinity for IGF-2 [22-25] which may explain increase of its levels in culture medium during the course of the study. In general, proteins of the IGF family have a profound impact on embryo and placenta development $[5,19$, 26]. It was observed in a mouse model that placental weight correlated with foetal weight, and these parameters were correlated with cord blood levels of IGF-1 and -2 [5]. Moreover, IGF-1 and IGF-2 levels were also significantly lower in umbilical cord blood sera of foetuses with growth retardation compared to normal foetuses [5]. In the mouse model, disruption of one of the IGF-2 alleles caused death of about $60 \%$ of mice [5].

Relative proportions of cells may influence the amount of factors released by amniotic cells. In accord with general knowledge, we found that the amniotic membrane comprised mainly two types of cells, mesenchymal and epithelial cells. Surprisingly, we found that factors released from the amniotic membrane circles were different from those released from Cell Fractions 1 and 2. One explanation for this observation may be that the relative proportion of growth factors released by the different cell fractions are depended on the interactions between cells present in the tested cultures. Indeed, our cultures comprised quite different proportions of the different cell types. Cell Fraction 1 contained a high proportion of mesenchymal cells (86\% cells with CD73+ phenotype); hAM cultures comprised both hAMSCs and hAECs (about $45 \%$ hAMSC and 55\% hAEC cells); and Cell Fraction 2 comprised mainly cells that expressed cytokeratin, which suggested that it comprised mainly hAECs, consistent with the cited procedure [6]. Moreover, the growth factors and receptors released by Cell Fraction 2 cultures were quite different from those released by other cultures.

An alternative explanation for the differences between the types and proportions of growth factors released between cell fractions and hAMs may be related to the type of culture media used. It is known that culture medium may affect expression of cell markers [27-29]. We have used serum-free RPMI
1640 as a culture medium which should have minimal impact on amnion in vitro to mimic in vivo conditions.

We are aware that human amnions release many more active biological factors, however, in this study we were limited by the 41 factors of the applied protein array.

In our experiment on HUVEC culture we observed more intensive migration of HUVEC in cultures with addition of $24 \mathrm{~h} \mathrm{hAM}$ culture medium, than without the addition. Also, our experiment showed that IGF- 2 was continually released into the culture media of cultured hAM over the $48 \mathrm{~h}$ time period. Bid et al. suggested role for IGF-2 in angiogenesis on HUVECs culture model [30]. We propose that the observed migratory effect on HUVEC may be due to the IGF-2 presence in the $24 \mathrm{~h}$ hAM culture medium or appearance of other released, however, not tested factors.

In conclusion, we showed that protein-free culture media conditioned by human amnion or isolated amniotic cell populations contained several growth factors and receptors. The presence and secretion of several growth factors in human amnion membranes and amniotic cells was observed for the first time. It may be suggested that amnion and amniotic cells might be a source of valuable growth factors for regenerative medicine.

\section{Conflict of interest statement}

This work was supported by the European Union Innovative Economy Operational Program: Innovative methods of stem cell applications in medicine (01.01.02-00-109/09-00). The authors report no conflicts of interest.

\section{References}

1. Parolini O, Alviano F, Bagnara GP et al. Concise review: isolation and characterization of cells from human term placenta: outcome of the first international Workshop on Placenta Derived Stem Cells. Stem Cells. 2008;26:300-311.

2. Astern JM, Collier AC, Kendal-Wright CE. Pre-B cell colony enhancing factor (PBEF/NAMPT/Visfatin) and vascular endothelial growth factor (VEGF) cooperate to increase the permeability of the human placental amnion. Placenta. 2013;34:42-49.

3. Grzywocz Z, Gawryluk A, Noszczyk B. Amnion membrane: structure, functions and applications in regenerative medicine. Adv Cell Biology. 2012;39:637-652.

4. Fried G, Sand A, Ostlund E et al. Endothelin-1 and macrophage colony-stimulating factor are co-localized in human amnion membrane cells and secreted into amniotic fluid. $\mathrm{Mol}$ Hum Reprod. 2003;9:719-724.

5. Millar LK, Reiny R, Yamamoto SY et al. Relaxin causes proliferation of human amniotic epithelium by stimulation of insulin-like growth factor-II. Am J Obstet Gynecol. 2003;188:234-241. 
6. Soncini M, Vertua E, Gibelli L et al. Isolation and characterization of mesenchymal cells from human fetal membranes. J Tissue Eng Regen Med. 2007;1:296-305.

7. Hwang JH, Lee MJ, Seok OS et al. Cytokine expression in placenta-derived mesenchymal stem cells in patients with pre-eclampsia and normal pregnancies. Cytokine. 2010;49:95-101.

8. Kim J, Kang HM, Kim $\mathrm{H}$ et al. Ex vivo characteristics of human amniotic membrane-derived stem cells. Cloning Stem Cells. 2007;9:581-594.

9. Mamede AC, Carvalho MJ, Abrantes AM at al. Amniotic membrane: from structure and functions to clinical applications. Cell Tissue Res. 2012;349:447-458.

10. Miki T. Amnion-derived stem cells: in quest of clinical applications. Stem Cell Res Ther. 2011;2:25-36.

11. Vuorela P, Erika Hatva E, Lymboussaki A et al. Expression of Vascular Endothelial Growth Factor and Placenta Growth Factor in human placenta. Biol Reprod. 1997;56:489-494.

12. Floss T, Arnold HH, Braun T. A role for FGF-6 in skeletal muscle regeneration. Genes \& Development. 1997;11: 2040-2051.

13. English AW, Meador W, Carrasco DI. Neurotrophin- $4 / 5$ is required for the early growth of regenerating axons in peripheral nerves. Eur J Neurosci. 2005;21:2624-2634.

14. Ikomi F, Kawai Y, Nakayama J et al. Critical roles of VEGF-C-VEGF receptor 3 in reconnection of the collecting lymph vessels in mice. Microcirculation. 2008;15:591-603.

15. Manoranjan SJ, Faizuddin M, Hemalatha M et al. The effect of platelet derived growth factor- $\mathrm{AB}$ on periodontal ligament fibroblasts: An in vitro study. J Indian Soc Periodontol. 2012;16:49-53.

16. Ribeiro ML, Ogando D, Farina M et al. Epidermal growth factor modulation of prostaglandins and nitrite biosynthesis in rat fetal membranes. Prostaglandins Leukot Essent Fatty Acids. 2004;70:33-40.

17. Shobokshi A, Shaarawy M. Maternal serum and amniotic fluid cytokines in patients with preterm premature rupture of membranes with and without intrauterine infection. Int J Gynaecol Obstet. 2002;79:209-215.

18. Gope ML, Gope R. Tyrosine phosphorylation of EGF-R and PDGF-R proteins during acute cutaneous wound healing process in mice. Wound Repair Regen. 2009;17:71-79.

19. Han VK, Bassett N, Walton J et al. The expression of insulin-like growth factor (IGF) and IGF-binding protein (IGFBP) genes in the human placenta and membranes: evidence for IGF-IGFBP interactions at the feto-maternal interface. J Clin Endocrinol Metab. 1996;81:2680-2693.

20. Hill DJ, Clemmons DR, Riley SC et al. Immunohistochemical localization of insulin-like growth factors (IGFs) and IGF binding proteins $-1,-2$ and -3 in human placenta and fetal membranes. Placenta. 1993;14:1-12.

21. Bach LA, Hsieh S, Sakano K et al. Binding of mutants of human insulin-like growth factor II to insulin-like growth factor binding proteins 1-6. J Biol Chem. 1993;268:9246-9254.

22. Greenall SA, Bentley JD, Pearce LA et al. Biochemical characterization of individual human glycosylated pro-insulin-like growth factor (IGF)-II and big-IGF-II isoforms associated with cancer. J Biol Chem. 2013;288:59-68.

23. Qiu Q, Yan X, Bell M et al. Mature IGF-II prevents the formation of "big" IGF-II/IGFBP-2 complex in the human circulation. Growth Horm IGF Res. 2010;20:110-117.

24. Storch S, Kübler B, Höning $\mathrm{S}$ et al. Transferrin binds insulin-like growth factors and affects binding properties of insulin-like growth factor binding protein-3. FEBS Lett. 2001;509:395-398.

25. Burger AM, Leyland-Jones B, Banerjee Ket al. Essential roles of IGFBP-3 and IGFBP-rP1 in breast cancer. Eur J Cancer. 2005;41:1515-1527.

26. Carter AM, Kingston MJ, Han KK et al. Altered expression of IGFs and IGF-binding proteins during intrauterine growth restriction in guinea pigs. J Endocrinol. 2005;184:179-189.

27. Adamzyk C, Emonds T, Falkenstein J et al. Different culture media affect proliferation, surface epitope expression, and differentiation of ovine MSC. Stem Cells Int. 2013;2013: 387 324-387 337.

28. Hagmann S, Moradi B, Frank S et al. Different culture media affect growth characteristics, surface marker distribution and chondrogenic differentiation of human bone marrow-derived mesenchymal stromal cells. BMC Musculoskelet Disord. 2013;30:223-234.

29. Mark P, Kleinsorge M, Gaebel R et al. Human Mesenchymal Stem Cells Display Reduced Expression of CD105 after Culture in Serum-Free Medium. Stem Cells Int. 2013;2013: $698076-698084$.

30. Bid HK, Zhan J, Phelps DA et al. Potent inhibition of angiogenesis by the IGF-1 receptor-targeting antibody $\mathrm{SCH} 717454$ is reversed by IGF-2. Mol Cancer Ther. 2012;11:649-659.

Submitted: 7 July, 2014

Accepted after reviews: 24 September, 2014 